\title{
Teaching the Social Determinants of Health in Undergraduate Medical Education: a Scoping Review
}

\author{
Ashti Doobay-Persaud, MD ${ }^{1,2}$, Mark D. Adler, MD ${ }^{3,4}$, Tami R. Bartell, MPH', Natalie E. Sheneman', \\ Mayra D. Martinez ${ }^{2}$, Karen A. Mangold, MD, MEd ${ }^{3,4}$, Patricia Smith, MLIS , and Karen M. Sheehan, \\ $M D, M P H^{3}$
}

\begin{abstract}
'Division of Hospital Medicine, Department of Medicine, Northwestern University Feinberg School of Medicine, Chicago, IL, USA; ${ }^{2}$ Center for Global Health, Northwestern University Feinberg School of Medicine, Chicago, IL, USA; ${ }^{3}$ Department of Pediatrics, Northwestern University Feinberg School of Medicine, Chicago, IL, USA; ${ }^{4}$ Department of Medical Education, Northwestern University Feinberg School of Medicine, Chicago, IL, USA; ${ }^{5}$ Mary Ann \& J. Milburn Smith Child Health Research, Outreach and Advocacy Center, Stanley Manne Children's Research Institute, Ann \& Robert H. Lurie Children's Hospital of Chicago, Chicago, IL, USA; ${ }^{6}$ Galter Health Sciences Library, Northwestern University Feinberg School of Medicine, Chicago, IL, USA.
\end{abstract}

BACKGROUND: To provide optimal care, medical students should understand that the social determinants of health (SDH) impact their patients' well-being. Those charged with teaching SDH to future physicians, however, face a paucity of curricular guidance.

OBJECTIVE: This review's objective is to map key characteristics from publications about teaching SDH to students in undergraduate medical education (UME).

METHODS: In 2016, the authors searched PubMed, Embase, Web of Science, the Cochrane and ERIC databases, bibliographies, and MedEdPORTAL for articles published between January 2010 and November 2016. Four reviewers screened articles for eligibility then extracted and analyzed data descriptively. Scoping review methodology was used to map key concepts and curricular logistics as well as educator and student characteristics.

RESULTS: The authors screened 3571 unique articles of which 22 were included in the final review. Many articles focused on community engagement (15). Experiential learning was a common instructional strategy (17) and typically took the form of community or clinic-based learning. Nearly half (10) of the manuscripts described school-wide curricula, of which only three spanned a full year. The majority of assessment was self-reported (20) and often related to affective change. Few studies objectively assessed learner outcomes (2).

CONCLUSIONS: The abundance of initial articles screened highlights the growing interest in SDH in medical education. The small number of selected articles with sufficient detail for abstraction demonstrates limited SDH curricular dissemination. A lack of accepted tools or practices that limit development of robust learner or program evaluation was noted. Future research should focus on identifying and evaluating effective instructional and assessment methodologies to address this gap, exploring additional innovative teaching frameworks, and examining the specific contexts and characteristics of

Electronic supplementary material The online version of this article (https://doi.org/10.1007/s11606-019-04876-0) contains supplementary material, which is available to authorized users.

Published online April 16, 2019 marginalized and underserved populations and their coverage in medical education.

KEY WORDS: social determinants of health; undergraduate medical education; health equity; scoping review.

J Gen Intern Med 34(5):720-30

DOI: $10.1007 / \mathrm{s} 11606-019-04876-0$

(c) Society of General Internal Medicine 2019

\section{BACKGROUND}

Individuals and groups who have been marginalized and who have suffered discrimination have demonstrably poorer health outcomes. ${ }^{1-6}$ In response to these health disparities, the National Academies of Sciences, Engineering, and Medicine $\left(\right.$ NASEM) ${ }^{1,7}$ and governing bodies ${ }^{8-10}$ have issued urgent calls to prepare health professional students to address the social determinants of health (SDH) at the patient and community level. SDH must be both understood and addressed in order to achieve health equity. ${ }^{11-16}$ Medical educators and academic medical centers (AMCs) are now charged with developing physicians who will advocate for the most vulnerable members of our society. ${ }^{17-21}$

Young physicians must understand that the SDH, defined by the World Health Organization (WHO) as the "conditions in which people are born, grow, live, work, and age," inform their patients' health and are within their purview. ${ }^{16,22}$ This requires perspective shifts for both the educator and the learner, with the desired educational outcome being transformative learning. ${ }^{23-25}$ (Textbox 1) There are a variety of existing instructional frameworks for SDH teaching. Examples of these include the biopsychosocial ${ }^{26}$ and structural competency models, ${ }^{27-29}$ service-learning pedagogy ${ }^{1,20,30,31}$ with critical reflection ${ }^{28,29,32}$ (Textbox 1), and curricula that are experiential, longitudinal, interprofessional, and community-based. ${ }^{1,27,29,31-33}$ Transformative learning is often the goal in service learning and requires the critical assessment of the learner's assumptions and 
experiences, to reframe perspectives and inform future actions via critical reflection (Textbox 1).

Textbox 1. Definitions used in "Teaching the Social Determinants of Health in Undergraduate Medical Education: A Scoping Review"

\section{Transformative Learning}

A theory of learning that is beyond basic knowledge or skill acquisition whereby the learner's assumptions and perspectives are transformed via experiential learning; facilitated structured reflective dialogue and high level analysis. These new beliefs and insights are then applied to current and future actions and critically assessed. ${ }^{24,25}$

Service Learning

Community-based learning that balances service and learning through a structured service experiential curriculum with central tenets of reflection and true community engagement. ${ }^{1,22,31,34}$

\section{Critical Reflection}

A process within the experiential learning cycle whereby the learner becomes aware of their own assumptions and preconceived notions through assessing, questioning, criticizing their actions and the experience with the goal of reframing perspective and using this analysis to inform future behavior. ${ }^{25,26,32}$

Given both the need to incorporate SDH content and continued calls for curricular guidance, ${ }^{1,35,36}$ we performed a scoping review to answer the research question: "What has been published on the topic of teaching medical students about the social determinants of health?" We used scoping methodology to map key concepts and logistics, as well as educator and student characteristics from the SDH medical literature. We sought to both provide a resource for educators and identify gaps and opportunities for future research.

\section{METHODS}

We conducted a scoping review based on existing frameworks. ${ }^{37-39}$ We followed the recommended five stages: (1) formulating the research question, (2) identifying relevant studies, (3) study selection, (4) charting data, and (5) collating, summarizing, and reporting results.

\section{Stage 1: Formulating the Question}

Our research team had experience in curricular design, implementation, and assessment in general medical education and specific to the SDH domain. We collaborated with an experienced medical librarian in our scoping process. Together, we determined the broad and specific research questions, designed the study protocol, reviewed search terms, and identified target databases.

We chose a scoping review to answer the general research question: "What has been published on the topic of teaching medical students about the social determinants of health?" The term SDH was selected as it was the language used in guidelines published by national associations of North American medical schools. ${ }^{40,41}$ We defined social determinants of health a priori, and used the definition proposed by the WHO. As shown in Figure 1, the WHO describes the SDH as those intermediary factors and circumstances, along with the health system, that have an impact on equity in health and wellbeing. ${ }^{42}$ Our specific question focused on educational interventions to assist those educators seeking curricular guidance on implementation. We also sought to identify gaps in the literature to inform future research. ${ }^{43}$ Our goal was not to rate the quality of evidence or come to conclusions about best practices, but to offer the scope of available published knowledge about teaching the $\mathrm{SDH} .{ }^{44}$

Stage 2: Identifying Relevant Studies: Data Sources and Search Strategy

Our search strategy is shown in Textbox 2. We searched databases PubMed, Embase, Web of Science, the Cochrane Database, and the Educational Resources Information Center (ERIC) on November 14, 2016. The term "social determinants of health" was not indexed as a Medical Subject Heading until $2014 .{ }^{45}$ To address this issue, we began with a list of general and related keywords that often appear alongside the SDH in the current literature. References from the NASEM report on teaching the $\mathrm{SDH}^{1}$ and a Lancet Series on the health-poverty gap $^{2-6}$ were also searched. Finally, we searched MedEdPORTAL for relevant articles using the term "social determinants of health" (Online Supplementary Appendix).

Textbox 2. PubMed search strategy used for "Teaching the Social Determinants of Health in Undergraduate Medical Education: A Scoping Review"

\section{Stage 3: Study Selection}

A three-round process was used to determine article relevance, with multiple authors independently reviewing studies in each round (Fig. 2). After duplicate removal, references were imported into the web application Rayyan ${ }^{46}$ (http:// rayyan.qcri.org), which allowed blinded collaborative screening of results. In round 1, two reviewers (TB and KS) independently performed title and abstract screening based on content relevance, without limits on publication date, location, or study population. Four reviewers (TB, KS, ADP, MM) performed further abstract screening in round 2, applying the final inclusion criteria. Full-text screening was then done by the four reviewers (ADP, KS, TB, MA) during round 3. Discrepancies were resolved by consensus or involvement of an additional reviewer. 


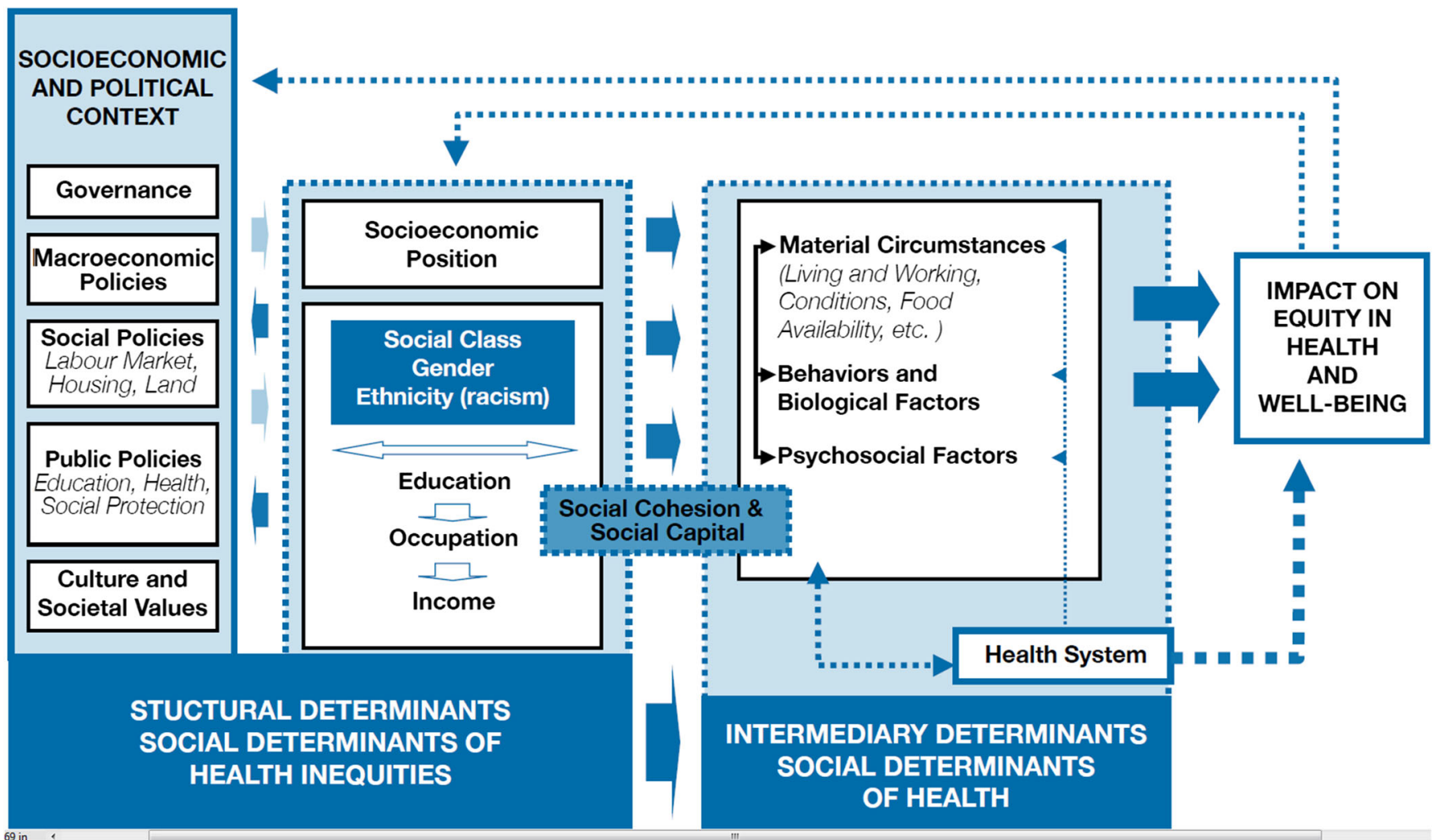

Figure 1 Final form of the Commission on Social Determinants of Health Conceptual Framework. ${ }^{42}$

We included English language articles published between 2010 and 2016 in North America. We chose the timeframe based on successive curricular mandates issued by the North American accreditation bodies for medical schools from 2010
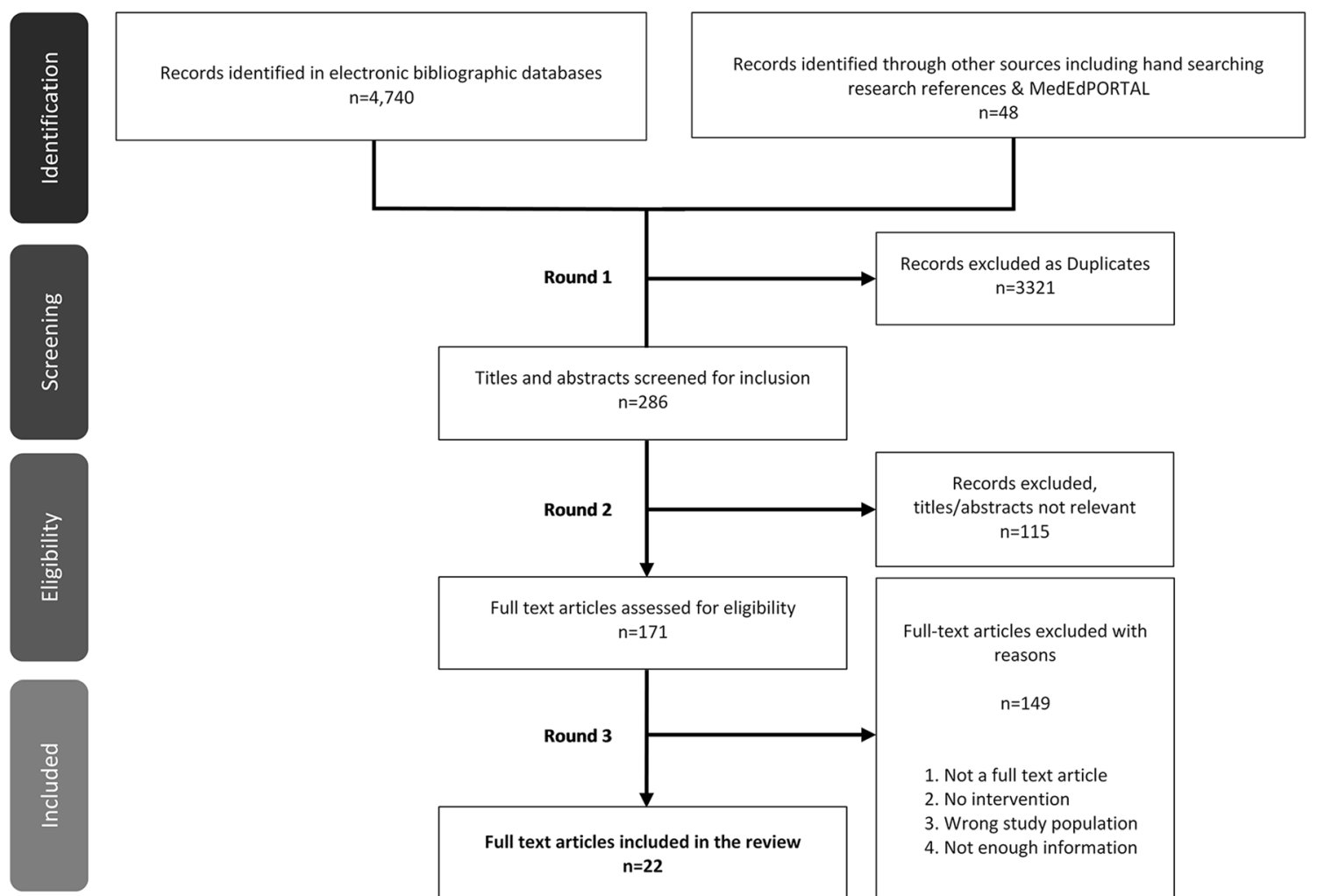
$\mathrm{n}=48$

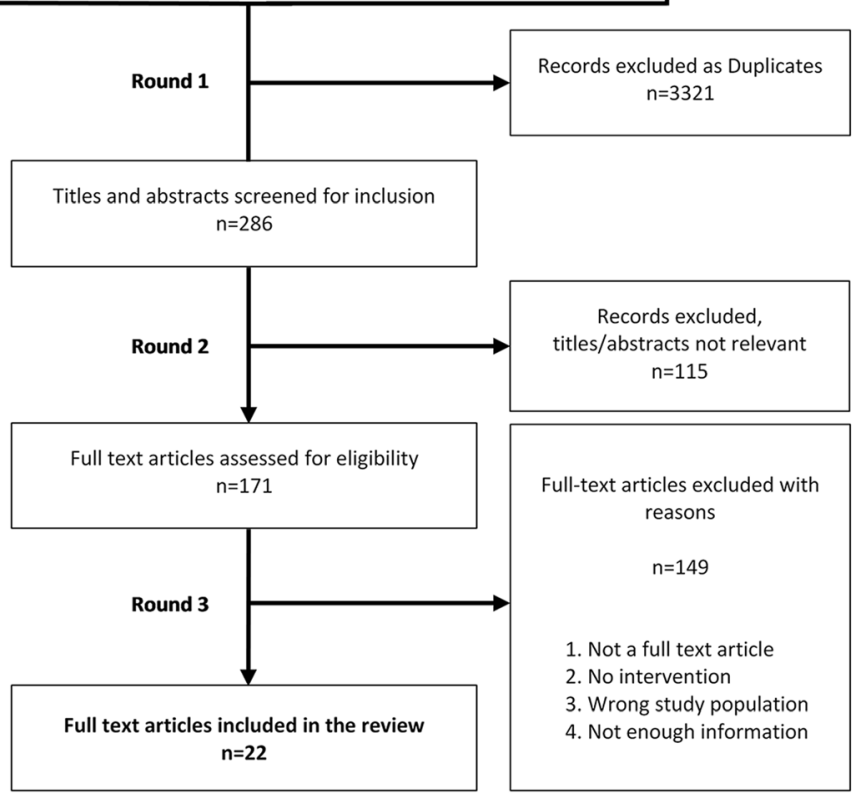

Figure 2 Scoping review flowchart of the literature search and selection process of studies in "Teaching the Social Determinants of Health in Undergraduate Medical Education: A Scoping Review." 
to $2015.8,9,47$ We excluded articles describing interventions that were a single event, as they did not provide sufficient curricular breadth. The final article types reviewed were original research, perspectives, reflections, and program reports. Despite their heterogeneity, these formats offered valuable information about SDH curricula.

Stage 4: Charting the Data

We abstracted data from all selected articles. Our recording form included manuscript details (author, year, journal, institution, funding source) and the following categories: (a) content/topic, (b) educational methods, (c) timing, (d) educator, (e) learner characteristics, (f) evaluation, and (g) funding. This methodology has been supported by Levac ${ }^{38}$ and Arksey and $\mathrm{O}^{\prime}$ Malley ${ }^{37}$ and used in similar studies. ${ }^{48,49}$

Stage 5: Collating, Summarizing, and Reporting Results

During the data abstraction stage, text from each article was selected and assigned a relevant category by a research assistant and a reviewer (MM, ADP). A second research assistant (NS) and two other authors (TB, KS) then reviewed and edited the data for accuracy. Data analysis involved assessment for qualitative themes and frequency analysis of program characteristics which was conducted by four authors (ADP, KS, MA, NS) with any discrepancies resolved by consensus. Some concepts or themes were infrequent but followed currently recommended curricular strategies. ${ }^{1,7,27,50}$ These were retained as having value to our effort. We excluded studies focused on cultural humility, cultural awareness, and implicit bias as these constructs and their associated instructional approaches have been extensively covered in the literature. ${ }^{34,51-58}$

We separated publications that reported student-level evaluation from those that reported alternative assessments or had a different focus (Tables 1 and 2).

\section{RESULTS}

The outcome of our search strategy is shown in Figure 2. We identified 3571 unique articles for title and abstract screening. Two-hundred and eighty-six articles were selected for round 2 screening, which yielded 171 articles for full-text review. The distribution of articles across journals was wide but journals rarely published more than three articles each. Notable exceptions were the Journal of General Internal Medicine (36), Academic Medicine (21), Medical Teacher (7), Medical Education (6), and the Rhode Island Medical Journal (5) (Online Supplementary Appendix). Out of 36 entries identified from the MedEdPORTAL review, five were included after abstract screening and only one met our inclusion criteria. None of the articles identified from reference list searches were included in the final review.

Of the 171 articles that underwent full-text review in round 3,22 were selected for final analysis in this study. The remaining 149 were excluded as unrelated to the topic, lacking detail regarding curricula, or failing to meet the original inclusion criteria. In some cases, multiple included articles contained content referencing the same program but provided details about different program aspects. We felt that the content was sufficiently detailed in each report for the described interventions to be considered separately.

\section{Topic/Content}

We abstracted program goals, content taught, and learning objectives and noted a wide variety of themes. All articles described program content that included definitions of the SDH and the mechanisms through which they impact an individual and population's health, particularly the underserved. The most common themes identified in this category were course content focused on community engagement ${ }^{59,61}$, $62,65,66,68-71,73-76,78,80$ (15); understanding the local context $^{60,61,64,68-70,72,76,79}(11)$; health policy and advocacy teaching ${ }^{59-65,67,73}$ (9); and professional development for students $^{59-61,63,70,75,80}$ (7). Other notable content themes referenced in a minority of articles were population health ${ }^{72}$ (1), diversity ${ }^{62,68,78}$ (3), and leadership ${ }^{70,73,78,80}$ (4). Because of the wide range in topics and content, these themes were not included in our final tables.

\section{Educational Methods}

All articles except for Powell and Bullock explicitly described programs that used traditional didactic forms of instruction ${ }^{59-77}$,

79 (20) and many described participatory components that were also classroom-based: case-based instruction ${ }^{59,} 60,63,69,70,73,77$ (7); small group work ${ }^{61,63,69,77,80}$ (5); and peer teaching ${ }^{59,} 66$, $67,71,78(5)$. All learner-led activities were considered participatory within our charting scheme.

Traditional instructional strategies were often complemented by experiential learning ${ }^{59,} 61-63,65-72,74-76,78,80$ (17) that took the form of either clinic or community-based education (Tables 1 and 2). Experiential learning was defined as activities involving direct interactions with patients, families, and communities. Clinic-based learning was integrated into clerkships or electives $^{59,66,67,71,78}$ (5). Community-based education took the form of service projects ${ }^{61,62,65,66,68,70,71,73-75,78,80}(12)$; community-based participatory research ${ }^{62,74}(2)$; and neighborhood tours ${ }^{69,72,75}$ (3). Longitudinal community collaborations were detailed in three studies. ${ }^{61,62,71}$ In one example, described by Haq and colleagues, students in the TRIUMPH Community Health Course at University of Wisconsin engaged consistently throughout the program with community health projects using a service-learning model.

Reflection was described in nine articles. ${ }^{60,65-67,73,75-77,80}$ Critical reflection was cited as an instructional strategy in six articles. ${ }^{65,67,75-77,80}$ Bernstein $^{76}$ used critical reflection as a learning tool and as part of program assessment. Bullock ${ }^{80}$ described a community-led collaboration where critical reflection is facilitated by faculty and through post-intervention dialogue with community members. 


$$
\text { 窇 }
$$

产

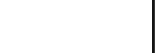

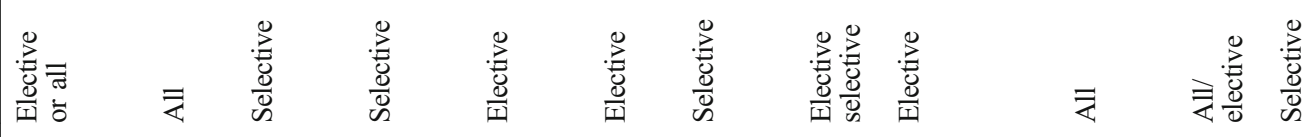

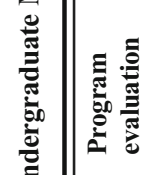

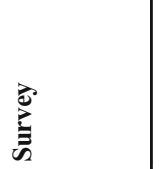

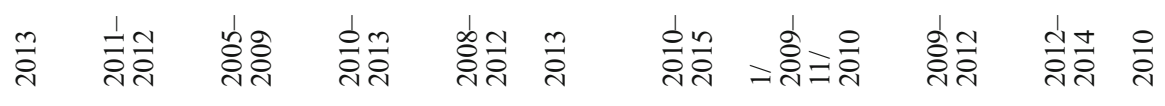




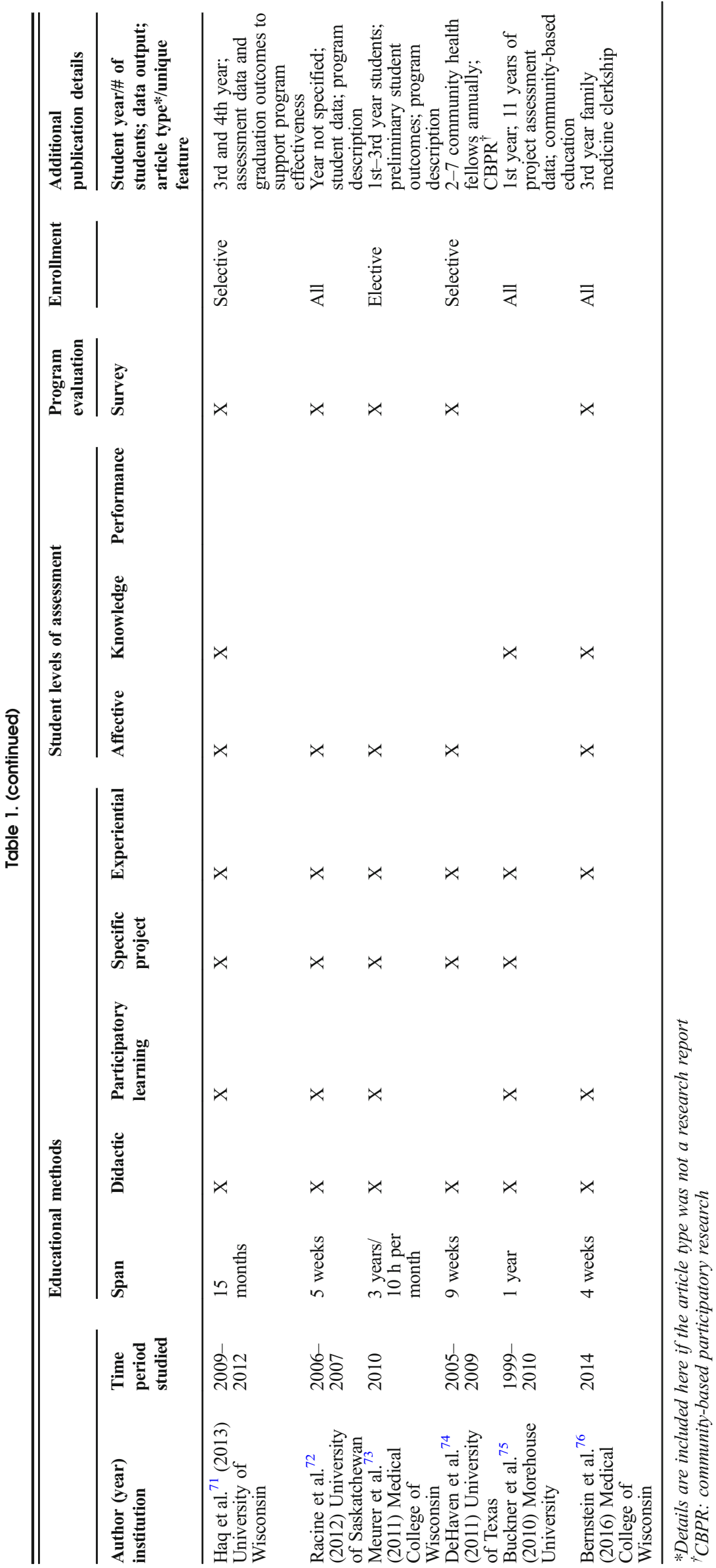


Table 2 Curricular Logistics of Relevant Publications Included in "Teaching the Social Determinants of Health in Undergraduate Medical Education: A Scoping Review"

\begin{tabular}{|c|c|c|c|c|c|c|c|}
\hline \multirow[b]{2}{*}{$\begin{array}{l}\text { Author (year) } \\
\text { institution }\end{array}$} & \multicolumn{5}{|c|}{ Educational methods } & \multirow[t]{2}{*}{ Enrollment } & \multirow[t]{2}{*}{ Program and article details } \\
\hline & Span & Didactic & $\begin{array}{l}\text { Participatory } \\
\text { learning }\end{array}$ & $\begin{array}{l}\text { Specific } \\
\text { project }\end{array}$ & Experiential & & \\
\hline $\begin{array}{l}\text { Kothari et al. }{ }^{77} \text { (2014) } \\
\text { Harvard University }\end{array}$ & Semester & $\mathrm{X}$ & $\mathrm{X}$ & & & All & $\begin{array}{l}\text { 1st year; opinion paper } \\
\text { describing introduction to } \\
\text { social medicine course }\end{array}$ \\
\hline $\begin{array}{l}\text { Powell et al. }{ }^{78} \text { (2016) } \\
\text { University of } \\
\text { California, San Diego }\end{array}$ & 4 years & $\mathrm{X}^{*}$ & $\mathrm{X}$ & $\mathrm{X}$ & $\mathrm{X}$ & Selective & $\begin{array}{l}10 \text { students per year; } 75 \% \\
\text { multilingual; graduation and } \\
\text { diversity statistics; master's } \\
\text { degree; community } \\
\text { engagement and scholarly } \\
\text { work }\end{array}$ \\
\hline $\begin{array}{l}\text { White et al. }{ }^{79}(2014) \\
\text { Brown University }\end{array}$ & 6 weeks & $\mathrm{X}$ & $\mathrm{X}$ & & & All & $\begin{array}{l}\text { Details of family medicine } \\
\text { clerkship; details on } \\
\text { community } \\
\text { educators and site projects }\end{array}$ \\
\hline $\begin{array}{l}\text { Bullock et al. (2014) } \\
\text { Georgetown Universi- } \\
\text { ty }\end{array}$ & 3 semesters & $X^{*}$ & $X$ & $\mathrm{X}$ & $X$ & All & $\begin{array}{l}\text { 1st year students; history; } \\
\text { learning objectives; details } \\
\text { on service learning; context } \\
\text { and case study }\end{array}$ \\
\hline
\end{tabular}

*Not described explicitly but occurrence is implied in program description

Erlich $^{69}$ described a comprehensive, multimodal SDH curriculum, created by students and developed using Kern's model. ${ }^{81}$ In their approach, advanced learning objectives were integrated successively throughout the four-year undergraduate medical experience. Focusing on health disparities, the curriculum began with classroom- and community-based activities in the pre-clinical years and was followed by a required family medicine clerkship that included SDH content.

\section{Curricular Logistics: Timing, Duration, and Learner Characteristics}

In this section, we describe the curricular logistics of timing and learner characteristics both separately and in relation to one another. We did this to better convey the intensity of the programs as well as the learner groups that were targeted. The final categories for program duration were short-term $(\leq$ 6 weeks), intermediate (6 weeks-1 year), and longitudinal ( $>1$ year). Short-term interventions were either required as part of first year orientation or were a component of a longer clerkship $^{59,67,68,72,76}$ (5). Seven articles described intermediate initiatives ranging from a single course or clerkship ${ }^{64,74}$, ${ }^{79}$ through programs that spanned months. ${ }^{63,65,77,80}$ Nine of the articles described longitudinal community-based SDH curricula over a span of one year or more. ${ }^{61,62,66,69-71,73 \text {, }}$ 75, 78 Timing is described in greater detail under program/ publication type in Tables 1 and 2.

Articles were also classified by the described programs' availability to all students. These categories were required for all learners, required for some learners, and elective or selective-requiring an application process (Tables 1 and 2). In total, 10 manuscripts described curricula geared to all undergraduate medical students. ${ }^{59,60,68,69,72,75-77,79,80}$ Only three of these articles reported curricula that were close to a year or more. ${ }^{69,} 75,80$ Buckner $^{75}$ and Bullock ${ }^{80}$ both described community-based coursework throughout the first year of medical school, and the program described by Erlich ${ }^{69}$ was integrated throughout all four years. Four other articles outlined SDH curricula for all medical students that were classified as short-term in duration. ${ }^{59,68,72,76}$

The remaining 12 articles described selective or elective courses (Tables 1 and 2). ${ }^{61-67,70,71,73,74,78}$ It is notable that the learner characteristics sought by selective programs generally included a desire to work or experience working in resource-constrained settings, fluency in another language, interest in primary care, and strong service ethic. Six of the articles detailed selective programs that were longitudinal in duration. ${ }^{61,62,66,70,71,78}$ The UMed program at the University of Illinois at Chicago College of Medicine, described by Girotti, ${ }^{62}$ was one of the most selective programs and followed a longitudinal four-year curriculum. Other similar selective pathways were integrated and longitudinal for one year, like the Icahn Human Rights and Social Justice Scholars Program described by Bakshi ${ }^{61}$ or spanning several years. ${ }^{70,}$ 71, 73, 78 Powell $^{78}$ described a curriculum for a narrow group of learners who intended to pursue a one-year Master's Degree in addition to their MD. A key feature of all longitudinal programs was sustained community engagement.

\section{Educators/Community Expert Engagement}

Most educators were university-based faculty with variable expertise in teaching SDH. Community members and other interprofessional educators were represented in several studies, but similar to other forms of community engagement described above, the participation of non-faculty educators ranged in intensity and importance across programs.

Educator descriptions fell into several categories: school faculty, interdisciplinary faculty, community educators, and peers or fellow students. All studies used medical school 
faculty as the educators and mentors with, when reported, variable expertise and support for teaching SDH (Tables 1 and 2). Nine studies involved community educators ${ }^{61,62,65-}$ $67,72-74,76$ and nine described the teaching role of other interdisciplinary professionals. ${ }^{60-62,65,68,69,72-74}$ Although these programs, as Girotti ${ }^{62}$ puts it, aimed to put the "community [expert] at the center of the educational experience," these individuals were typically limited to advising, facilitating, and collaborating on community projects. Three studies did move beyond this paradigm by soliciting formal feedback about students from the community representatives. $^{71,72,74} \mathrm{Haq}^{71}$ detailed this process: faculty asked the community collaborator about the "student's dedication to the project, curiosity/drive to learn, professionalism, and flexibility to adapt to circumstances." If it was not explicitly described in the article, we did not make assumptions about methodology, but we would expect that most workplace-based interventions had some component of interdisciplinary learning.

\section{Assessment Practices}

The categories that emerged from assessment descriptions were the following: survey or test, reflections, project evaluation, graduation outcomes, and feedback. Analysis of abstracted data revealed both student- and program-level assessments of the described teaching interventions.

Twenty articles contained affective student assessment, measuring self-reported changes in knowledge, skills, and attitudes; recognition of the impact of social determinants of health; and desire to serve the underserved. ${ }^{60-74,76-80}$ Student assessments about attitude change using the Medical Student's Attitudes Toward the Underserved ${ }^{82}$ instrument were described in three publications. ${ }^{62,66,68}$ Performance-based student assessment was discussed in four articles and limited to clinic-based curricula. ${ }^{59,}$ 66, 69, 70 Two studies described developing objective clinical skills examinations (OSCE) as a method of assessing both student and program effectiveness. ${ }^{59,66}$

Asgary integrated their curriculum on care for the homeless into clerkships and used multiple approaches to evaluate student outcomes. ${ }^{59}$ A direct clinical skills evaluation included a communication component assessing learner performance in obtaining a thorough social history and ability to validate patients' concerns. In the Brown University program, described by Anthony, ${ }^{66}$ three OSCE stations were developed in which students helped vulnerable clinic patients navigate health disparities. Three studies, geared to developing primary care physicians, reported comparative data about graduation outcomes to demonstrate program impact. ${ }^{62,71,78}$

Reflection practices were also used for student and program assessment. O'Brien ${ }^{65}$ and Buckner ${ }^{75}$ described using structured reflection prompts and facilitated feedback focusing on student assessment. Van den Heuvel ${ }^{67}$ and Duffy ${ }^{68}$ detailed the use of reflection to evaluate the effectiveness of their respective curricula. The former study described a social pediatrics elective, during which student reflections were analyzed to determine if transformative learning had occurred, based on a four-phase tool developed by a previous study. Additionally, Van den Heuvel and colleagues identified the specific aspects of the program that triggered instances of transformative learning.

In total, student performance data was used to support curricular effectiveness in six publications. 59, 65, 67, 68, 71, 78 All other program-level assessments, when reported, were drawn from student surveys. These took the form of student self-assessment and affective assessment of program elements (Tables 1 and 2).

\section{Funding}

Five distinct funding categories emerged from our review: government grants, philanthropy/endowment, no reported funding source, none, and university funds. Some studies reported different degrees of funding from multiple sources. There was no clear major finding given the variability in reporting and the different funding sources. However, it was notable that many educational interventions used additional resources outside of traditional institutional medical education funds.

\section{DISCUSSION}

Scoping reviews offer a unique opportunity to retrieve, scan, and disseminate a broad range of literature to answer a research question. This review adds to efforts by policy and accrediting bodies to support educators and institutions in the process of transforming health professionals' education to address the SDH. ${ }^{1,7-10,20,50}$

The number of articles retrieved highlights the growing interest in SDH in medical education. The small number of articles with sufficient detail on key areas for our study underscores the early stage of SDH curricular inclusion in undergraduate medical education (UME), the lack of tools to assess learner development and program impact, and the challenges associated with implementation and evaluation. Only a few programs reviewed used the framework recommend by the NASEM, incorporating three domains: education, community, and organization. ${ }^{1}$ Furthermore, programs that had all of these elements were typically only offered to self-selected students through a competitive application process.

We found that SDH content was heterogeneous outside of basic definitions and that while experiential learning was often described, instructional practices varied. Class-based instruction was consistently used and typically taught by university faculty members with variable expertise. Additionally, and perhaps most importantly, integrated and longitudinal curricula were described infrequently and only for select students.

Objective assessment was rarely described in the reviewed studies, appearing only twice. ${ }^{59,} 66$ Most assessments were subjective and self-reported by the learner. We recently published the results of a modified Delphi process that described 
the necessity for improved learner assessment for use in SDH curricula. This may reflect that SDH concepts are only now being integrated into medical education and that assessment of these concepts will be developed and disseminated over time. ${ }^{33,83}$

Although it rarely appeared in our review, educational research in other fields suggests that critical reflection is a valuable tool for transformation of learner attitudes toward vulnerable populations and structural injustice. ${ }^{23,32,84,85}$ True transformative learning, which typically employs both experiential learning and critical reflection, requires a skilled facilitator to teach and assess. ${ }^{1,7,32}$ Similarly, social justice, social medicine, and structural competency educational frameworks can offer new perspectives for learning and teaching. ${ }^{7}, 13,15$, $29,60,77,86$ Innovative simulations may provide a way to both teach and assess skills in addressing and managing SDH for health professionals. ${ }^{87,88}$

Many of the educational interventions identified were funded through either time-limited grants or other philanthropic sources. Our findings corroborate the many known barriers to optimal teaching and learning around the $\mathrm{SDH}$, specifically those of insufficient time and funding, as well as a lack of meaningful experiential learning led by expert faculty. ${ }^{1,7-10 \text {, }}$ $20,36,50$ These are challenges to the scalability and sustainability of SDH programs. AMCs, faculty, and students will need to prioritize SDH instruction as a core effort, comparable with the basic sciences, if these programs are to become sustainable.

\section{Limitations}

Our study was limited by the heterogeneity in detail provided. Authors rarely quantified contact hours over the described time period and had limited descriptions of the educator, the experiential learning component, and the assessment methods. Evaluation data were not always collected or reported. Our scoping review is also limited to educational efforts in the published literature. Current practices that were unpublished could not be evaluated.

In accordance with scoping review methodology, this is not a comprehensive description of the topic and therefore not all health-related social, environmental, and other factors were examined. Rather, this review focused primarily on the term "social determinants of health." As a result, our search strategy focused explicitly on these terms. We hope that our methodology can be applied to study the multitude of factors that impact health equity.

\section{CONCLUSIONS}

This study adds to the literature by providing a map of current instructional approaches as well as highlighting the state of research in the field on teaching SDH to medical students. We have identified a notable gap in the literature, and likely in SDH curricula, around teaching that is available to every medical student. Future research should take a closer look at this need, and at each of the curricular categories we identified. Our findings show that SDH education research lacks clearly defined instructional tools and strategies, evidence of consistent and universal application, and standardized competencies for educators. Furthermore, we need to know which methods work. SDH educators and researchers will need to examine approaches for robust assessment of student performance, program effectiveness, and ultimately, the impact of these on patient care. Our review also reaffirmed a need in medical education for more reliable funding sources to support SDH teaching. While health inequities cannot be solved by medicine or public health alone, as the National Academies (NASEM) report aptly states "medicine has always been about the application of science to those who are in need, who are suffering, or who are at risk." "These recommendations all require sustainable funding, prioritization, and curricular emphasis by institutional stakeholders. By providing students with opportunities to develop a more robust model of the SDH and health equity, we ensure that the next generation of physicians is providing better care for our most vulnerable patients.

Corresponding Author: Ashti Doobay-Persaud, MD; Center for Global Health, Feinberg School of Medicine, Northwestern University, Chicago, IL, USA (e-mail: a-doobay-persaud@northwestern.edu).

Funding This project is supported by the Health Resources and Services Administration (HRSA) of the US Department of Health and Human Services (HHS) under grant number UH1HP29963, Academic Units for Primary Care Training and Enhancement. This information or content and conclusions are those of the author and should not be construed as the official position or policy of nor should any endorsements be inferred by HRSA, HHS, or the US Government.

\section{Compliance with Ethical Standards:}

Conflict of Interest: The authors declare that they do not have a conflict of interest.

Publisher's Note: Springer Nature remains neutral with regard to jurisdictional claims in published maps and institutional affiliations.

\section{REFERENCES}

1. National Academies of Sciences Engineering Medicine. A Framework for educating health professionals to address the social determinants of health. Washington (DC): National Academies Press; 2016.

2. Bailey ZD, Krieger N, Agenor M, Graves J, Linos N, Bassett MT. Structural racism and health inequities in the USA: evidence and interventions. Lancet. 2017;389(10077): 1453-1463.

3. Bor J, Cohen GH, Galea S. Population health in an era of rising income inequality: USA, 1980-2015. Lancet. 2017;389(10077):1475-1490.

4. Dickman SL, Himmelstein DU, Woolhandler S. Inequality and the health-care system in the USA. Lancet. 2017;389(10077): 1431-1441.

5. Gaffney A, McCormick D. The Affordable Care Act: implications for health-care equity. Lancet. 2017;389(10077):1442-1452.

6. Wildeman C, Wang EA. Mass incarceration, public health, and widening inequality in the USA. Lancet. 2017;389(10077):1464-1474.

7. Bogard K, Murry VM, Alexander C eds. Perspectives on health equity and social determinants of health. National Academy of Medicine; 2017.

8. Liaison Committee on Medical Education. Functions and structure of a medical school. standards for accreditation of medical education programs leading to the M.D. degree (2010). http://lcme.org/publications/ \#Standards. Accessed November 28, 2018. 
9. Sherbino J, Bonnycastle D, Côte B, Flynn L. The CanMEDS 2015 Health Advocate Expert Working Group Report. http://www.royalcollege. ca/rcsite/documents/canmeds/health-advocate-ewg-report-e.pdf. 2014. Accessed November 28, 2018.

10. Learning objectives for medical student education-guidelines for medical schools: report I of the Medical School Objectives Project. Academic Medicine. 1999;74(1):13-18.

11. Braveman P, Egerter S, Williams DR. The social determinants of health: coming of age. Annu Rev Public Health. 2011;32(1):381-398.

12. Marmot MG, Wilkinson RG. Social determinants of health. Oxford; New York: Oxford University Press; 2006.

13. Farmer P, Kleinman A, Kim J, Basilico M. Reimagining global health: an introduction. University of California Press; 2013.

14. Marmot M, Friel S, Bell R, Houweling TA, Taylor S, Commission on social determinants of health. Closing the gap in a generation: health equity through action on the social determinants of health. Lancet. 2008;372(9650): 1661-1669.

15. Fee E, Brown TM. A return to the social justice spirit of Alma-Ata. American Journal of Public Health. 2015;105(6): 1096-1097.

16. Silver GA. Virchow, the Heroic Model in Medicine - Health-Policy by Accolade. American Journal of Public Health. 1987;77(1):82-88.

17. Learning objectives for medical student education-guidelines for medical schools: report I of the Medical School Objectives Project. Acad Med. 1999;74(1):13-18.

18. Westerhaus M, Finnegan A, Goldsmith J, Lyon E, Fox C, Morse M. Social justice should be a key part of educating health professionals. statnews.com. https://www.statnews.com/2017/04/07/social-justicehealth-education/. Published 2017. Accessed November 28, 2018.

19. Oandasan IF. Health advocacy: bringing clarity to educators through the voices of physician health advocates. Academic Medicine. 2005;80(10 Suppl):S38-S41.

20. Chokshi DA. Teaching about health disparities using a social determinants framework. J GEN INTERN MED. 2010;25 Suppl 2(S2):S182 S185. doi:https://doi.org/10.1007/s11606-009-1230-3.

21. Gruen RL, Pearson SD, Brennan TA. Physician-citizens-public roles and professional obligations. JAMA. 2004;291(1):94-98. doi:https://doi.org/ 10.1001/jama.291.1.94.

22. World Health Organization. Commission on the social determinants of health. http://www.who.int/social_determinants/en/. Accessed November 28, 2018 .

23. Mezirow $\mathbf{J}$. Fostering critical reflection in adulthood: a guide to transformative and emancipatory learning. Jossey-Bass Publishers; 1990.

24. Mezirow JE. Learning as transformation: critical perspectives on a theory in progress. the Jossey-Bass Higher and Adult Education Series.; 2000.

25. Galtung J. Violence, peace, and peace research. J Peace Res. 1969;(3):167-191.

26. Engel GL. The need for a new medical model: a challenge for biomedicine. Science. 1977; 196(4286):129-136.

27. Bourgois P, Holmes SM, Sue K, Guesada J. Structural vulnerability: operationalizing the concept to address health disparities in clinical care. Acad Med. 2017;92(3):299-307.

28. Metzl JM, Hansen H. Structural competency and psychiatry. JAMA Psychiatry. 2018;75(2):115-116. doi:https://doi.org/10.1001/ jamapsychiatry.2017.3891

29. Metzl JM, Hansen H. Structural competency: theorizing a new medical engagement with stigma and inequality. Soc Sci Med. 2014;103:126-133.

30. Yoder KM. A framework for service-learning in dental education. J Dent Educ. 2006;70(2):115-123.

31. Borges NJ, of PHIJ, 2007. Service learning in medical education: Project description and evaluation. https://digitalcommons.unomaha.edu/ slceslgen/50/. Accessed November 28, 2018.

32. Aronson L. Twelve tips for teaching reflection at all levels of medical education. Med Teach. 2011;33(3):200-205.

33. Sheehan K. AAMC Curriculum inventory in context. Social determinants of health in US and Canadian medical schools. https://www.aamc.org/ download/479480/data/ciic04-4apr2017.pdf. Published April 2017. Accessed November 28, 2018.

34. Kumagai AK, Lypson ML. Beyond cultural competence: critical consciousness, social justice, and multicultural education. Acad Med. 2009;84(6):782-787.

35. Frenk J, Chen L, Bhutta ZA, et al. Health professionals for a new century: transforming education to strengthen health systems in an interdependent world. The Lancet Commissions. 2010;376(9756):1923-1958.

36. Vakani FS, Zahidie A. Teaching the social determinants of health in medical schools: challenges and strategies. Journal of the College of Physicians and Surgeons-Pakistan: JCPSP. 2013;23(1):99-100.
37. Arksey H, O'Malley L. Scoping studies: towards a methodological framework. International Journal of Social Research Methodology. 2005;8(1): 19-32.

38. Levac D, Colquhoun H, O'Brien KK. Scoping studies: advancing the methodology. Implement Sci. 2010;5(1):69.

39. The Joanna Briggs Institute. The Joanna Briggs Institute reviewers manual 2015/Supplement. The Joanna Briggs Institute; 2015.

40. The Association of Faculties of Medicine of Canada Public Health Educators' Network. AFMC primer on population health "Chapter 2 determinants of health and health inequities." (Donovan D, McDowell I, eds.): 1-33.

41. AAMC. Teaching hospitals' commitment to addressing the social determinants of health. https://www.aamc.org/download/480618/data/ aamc-teaching-hospitals-addressing-sdoh.pdf. Accessed November 28, 2018.

42. Reprinted from Solar O, Irwin A. A conceptual framework for action on the social determinants of health. Policy and Practice. 2010.

43. Daudt HM, van Mossel C, Scott SJ. Enhancing the scoping study methodology: a large, inter-professional team's experience with Arksey and O'Malley's framework. BMC Med Res Methodol. 2013;13(1):48.

44. Pham MT, Rajic A, Greig JD, Sargeant JM, Papadopoulos A, McEwen SA. A scoping review of scoping reviews: advancing the approach and enhancing the consistency. Res Synth Methods. 2014;5(4):371-385.

45. Sivan SY. Mainstreaming social determinants of health (SDH) terms into the PubMed database would facilitate effective scrutiny of SDH. Social Medicine. 2014;8(3):139-142.

46. Ouzzani M, Hammady H, Fedorowicz Z, Elmagarmid A. Rayyan-a web and mobile app for systematic reviews. Syst Rev. 2016;5(1):210.

47. AOAMC, Liaison Committee on Medical Education. Functions and structure of a medical school. 2003. https://members.aamc.org/eweb/ u p 1 o a d /

Functions $\% 20$ and $\% 20$ Structure $\% 20$ of $\% 20 a \% 20$ Medical $\% 20$ School.pdf. Accessed November 28, 2018.

48. Bing-You R, Hayes V, Varaklis K, Trowbridge R, Kemp H, McKelvy D. Feedback for learners in medical education: what is known? A scoping review. Acad Med. 2017;92(9):1346-1354.

49. Lawrence C, Mhlaba T, Stewart KA, Moletsane R, Gaede B, Moshabela M. The hidden curricula of medical education: a scoping review. Acad Med. November 2017:1.

50. Martinez IL, Artze-Vega I, Wells AL, Mora JC, Gillis M. Twelve tips for teaching social determinants of health in medicine. Med Teach. 2014;37(7): 1-6.

51. Horvat L, Horey D, Romios P, Kis-Rigo J. Cultural competence education for health professionals. Cochrane Consumers and Communication Group, ed. Cochrane Database Syst Rev. 2014;55(5):CD009405.

52. Tervalon M, Murray-García J. Cultural humility versus cultural competence: a critical distinction in defining physician training outcomes in multicultural education. Journal of health care for the poor and underserved. 1998;9(2):117-125.

53. Betancourt JR, Green AR, Carrillo JE, Park ER. Cultural competence and health care disparities: key perspectives and trends. Health Affairs. August 2017.

54. Sawatsky AP, Beckman TJ, Hafferty FW. Cultural competency, professional identity formation and transformative learning. 2017;51(5):462464.

55. Gonzalez CM, Kim MY, Marantz PR. Implicit bias and its relation to health disparities: a teaching program and survey of medical students. Teaching and Learning in Medicine. 2014;26(1):64-71.

56. FitzGerald $\mathbf{C}$, Hurst $\mathbf{S}$. Implicit bias in healthcare professionals: a systematic review. BMC Medical Ethics 2017 18:1. 2017;18(1):19.

57. Sukhera J, Watling C. A framework for integrating implicit bias recognition into health professions education. Acad Med. 2018;93(1):35-40.

58. Godsil RD, Tropp LR, Goff PA, Equality JPTSO, 2014. The science of equality, volume 1: addressing implicit bias, racial anxiety, and stereotype threat in education and health care. equity.ucla.edu

59. Asgary R, Naderi R, Gaughran M, Sckell B. A collaborative clinical and population-based curriculum for medical students to address primary care needs of the homeless in New York City shelters : Teaching homeless healthcare to medical students. Perspect Med Educ. 2016;5(3): 154-162.

60. Kasper J, Greene JA, Farmer PE, Jones DS. All health is global health, all medicine is social medicine: integrating the social sciences into the preclinical curriculum. Acad Med. 2016;91(5):628-632.

61. Bakshi S, James A, Hennelly MO, et al. The Human Rights and Social Justice Scholars Program: a collaborative model for preclinical training in 
social medicine. Annals of global health. 2015;81(2):290-297. doi:https://doi.org/10.1016/j.aogh.2015.04.001.

62. Girotti JA, Loy GL, Michel JL, Henderson VA. The Urban Medicine Program: developing physician-leaders to serve underserved urban communities. Acad Med. 2015;90(12):1658-1666.

63. Gonzalez CM, Fox AD, Marantz PR. The evolution of an elective in health disparities and advocacy: description of instructional strategies and program evaluation. Acad Med. 2015;90(12):1636-1640.

64. Cole McGrew M, Wayne S, Solan B, Snyder T, Ferguson C, Kalishman S. Health policy and advocacy for New Mexico medical students in the family medicine clerkship. Fam Med. 2015;47(10):799-802.

65. O'Brien MJ, Garland JM, Murphy KM, Shuman SJ, Whitaker RC, Larson SC. Training medical students in the social determinants of health: the Health Scholars Program at Puentes de Salud. Advances in medical education and practice. 2014;5:307-314.

66. Anthony D, Rayess El F, Esquibel AY, George P, Taylor J. Building a workforce of physicians to care for underserved patients. Rhode Island medical journal (2013). 2014;97(9):31-35.

67. van den Heuvel $\mathbf{M}$, Au $\mathbf{H}$, Levin $\mathbf{L}$, Bernstein S, Ford-Jones $\mathbf{E}$ Martimianakis MAT. Evaluation of a social pediatrics elective: transforming students' perspective through reflection. Clin Pediatr (Phila). 2014;53(6):549-555.

68. Duffy FD, Miller-Cribbs JE, Clancy GP, et al. Changing the culture of a medical school by orienting students and faculty toward community medicine. Acad Med. 2014;89(12):1630-1635.

69. Erlich M, Blake R, Dumenco L, White J, Dollase RH, George P. Health disparity curriculum at the Warren Alpert Medical School of Brown University. Rhode Island medical journal (2013). 2014;97(9):22-25.

70. Williams BC, Mullan PB, Haig AJ, et al. Developing a professional pathway in health equity to facilitate curricular transformation at the University of Michigan Medical School. Acad Med. 2014;89(8):11531156.

71. Haq C, Stearns M, Brill J, et al. Training in Urban Medicine and Public Health: TRIUMPH. Acad Med. 2013;88(3):352-363.

72. Racine L, Proctor P, Jewell LM. Putting the world as classroom: An application of the inequalities imagination model in nursing and health education. Journal of Transcultural Nursing. 2012;23(1):90-99.

73. Meurer LN, Young SA, Meurer JR, Johnson SL, Gilbert IA, Diehr S. The urban and community health pathway: preparing socially responsive physicians through community-engaged learning. American journal of preventive medicine. 2011;41(4 Suppl 3):S228-S236.

74. Dehaven MJ, Gimpel NE, Dallo FJ, Billmeier TM. Reaching the underserved through community-based participatory research and service learning: description and evaluation of a unique medical student training program. Journal of Public Health Management and Practice:
JPHMP. 2011;17(4):363-368. doi:https://doi.org/10.1097/PHH. Ob013e3182214707.

75. Buckner AV, Ndjakani YD, Banks B, Blumenthal DS. Using servicelearning to teach community health: the Morehouse School of Medicine Community Health Course. Acad Med. 2010;85(10):1645-1651.

76. Bernstein $\mathbf{R}$, Ruffalo $\mathbf{L}$, Bower $\mathbf{D}$. A multielement community medicine curriculum for the family medicine clerkship. MedEdPORTAL Publications. 2016;12.

77. Kothari K. A piece of my mind. The case for social medicine. JAMA. 2014;311(24):2483-2484.

78. Powell T, Garcia KA, Lopez A, Bailey J, Willies-Jacobo L. University of California San Diego's Program in Medical Education-Health Equity (PRIME-HEq): Training Future Physicians to Care for Underserved Communities. Journal of Health Care for the Poor and Underserved. 2016;27(3):937-946.

79. White J, Heney J, Esquibel AY, Dimock C, Goldman R, Anthony D. Teaching and addressing health disparities through the family medicine social and community context of care project. Rhode Island medical journal (2013). 2014;97(9):26-30.

80. Bullock K, Jackson BR, Lee J. Engaging communities to enhance and strengthen medical education: Rationale and summary of experience. World Medical and Health Policy. 2014;6(2):133-141.

81. Thomas PA, Kern DE, Hughes MT, Chen BY. Curriculum development for medical education. JHU Press; 2015.

82. Crandall SJ, Volk RJ, Loemker V. Medical students' attitudes toward providing care for the underserved. Are we training socially responsible physicians? JAMA. 1993;269(19):2519-2523.

83. Mangold K. Expert consensus on the social determinants of health for undergraduate medical education curricula. Accepted 2018 (forthcoming)

84. Lishman J. Handbook for practice learning in social work and social care : knowledge and theory. Second. London: Philadelphia:Jessica Kingsley Publishers; 2007.

85. Cranton P. Professional Development as Transformative Learning. New perspectives for teachers of adults. The Jossey-Bass higher and adult education series. 1st ed. San Francisco; 1996.

86. Westerhaus M, Finnegan A, Haidar M, Kleinman A, Mukherjee J, Farmer P. The necessity of social medicine in medical education. Acad Med. 2015;90(5):565-568.

87. Hsieh DT, Coates WC. Poverty simulation: an experiential learning tool for teaching social determinants of health. Chen EH, ed. AEM Education and Training. 2018;2(1):51-54.

88. Gostelow N, Barber J, Gishen F, Berlin A. Flipping social determinants on its head: Medical student perspectives on the flipped classroom and simulated patients to teach social determinants of health. Med Teach. 2018; 2:1-8. 